\title{
Study on the system of calcined desulfurization gypsum - aluminate cement - slag powder cement
}

\author{
Xiong Zhang ${ }^{1}$, Hao Ren ${ }^{1}$, Tao $\mathrm{Ji}^{1}$, Gaoyu $\mathrm{Liao}^{1}$, and Yongjuan Zhang ${ }^{1,{ }^{*}}$ \\ ${ }^{1}$ Institute of Building Materials, Tongji University, Shanghai 201804 , China
}

\begin{abstract}
In this study, by adding a small amount of calcined desulfurization gypsum and aluminate cement into slag powder cement, the effects of calcined desulfurization gypsum and aluminate cement on the flowability, mechanical properties and volume stability of the composite cementitious system were studied. The results show that the mechanical properties and volume stability of the composite cementitious system can be improved by adding appropriate amount of calcined desulfurization gypsum and aluminate cement. For example, when the ratio of sulfur to aluminum is $0.5: 1$, the compressive strengths of calcined desulfurization gypsum-aluminate cement-slag powder cement composite cementitious system increases by $34 \%$ in 1 day, $8 \%$ in 180 days, the free expansion rates are less than $0.6 \%$, and the expansion stresses are less than tensile strengths. The volumes are stable. The hydration products of the system mainly include AFt, $\mathrm{Ca}(\mathrm{OH})_{2}$ and $\mathrm{C}-\mathrm{S}-\mathrm{H}$. During the hydration process, some of the calcined desulfurization gypsum will be converted into dihydrate desulfurization gypsum.
\end{abstract}

\section{Introduction}

Desulfurization gypsum (Flue gas desulfurization gypsum, FGD gypsum for short) is a by-product of desulfurization in coal-fired plants. Its main component is calcium sulfate dehydrate $\left(\mathrm{CaSO}_{4} \cdot 2 \mathrm{H}_{2} \mathrm{O}\right)$. If the desulfurization gypsum is stacked in the natural environment, it will not only occupy the land but also pollute the environment ([1-3],[5],[7-13]). Therefore, a large number of researchers are committed to the development and utilization of desulfurization gypsum, which is mainly used in the fields of cement retarder, building gypsum and so on ([2],[5]). In order to expand the application range of desulfurization gypsum, many scholars begin to study the effects of desulfurization gypsum on the performance of cement concrete system. Daxing Qian et al . studied the effects of desulfurization gypsum as auxiliary cementitious material on the mechanical properties of concrete, and confirmed that the addition of FGD gypsum can significantly improve the early strength of concrete ([11]). Yongjuan Zhang et al. studied the effects of desulfurization gypsum on the properties of desulfurization gypsum-metakaolin-cement composite system. It was found that desulfurization gypsum could delay the setting time of the composite system, improve the early strength and have a significant effect on the volume stability ([2]). Usually, in order to improve the early strength of cementitious system, steam curing can be adopted. Based on this, Gaoyu Liao et al. systematically studied the properties of cementdesulfurization gypsum-slag powder composite cementitious system under steam curing condition. It showed that the early strength of the composite cementitious system was not ideal under the condition of steam curing ([16]).

In order to solve the problem of insufficient early strength of desulfurization gypsum-slag powder cement composite cementitious system ([16]), this paper intends to add a small amount of aluminate cement to compensate the content of active alumina in the cementitious system. The strength, working performance and volume stability of desulfurization gypsumaluminate cement-slag powder cement system under steam curing were investigated. The types of hydration products of composite system were studied by XRD, and the kinetic process of calcium vanadite formation was analyzed. This subject aims to study the influence law of desulfurization gypsum and aluminate cement on slag powder cement system, solve the problem of insufficient early strength, and analyze its action mechanism, so as to provide the theoretical basis and scientific guidance for the resource utilization of desulfurization gypsum.

\section{General situation of test}

\subsection{Raw materials}

(1) Cement : Portland cement (P II 42.5). Its chemical composition is shown in Table 1.

(2) Slag powder : the S95 slag powder of Shanghai Baotian New Building Materials Co. Ltd., with a density of $2860 \mathrm{~kg} \cdot \mathrm{m}^{-3}$ and a specific surface area of $450 \mathrm{~m}^{2} \cdot \mathrm{kg}$.

(3) Desulfurization gypsum : from a power plant in Xiamen. Its chemical composition is shown in Table 2.

\footnotetext{
*Yongjuan Zhang: 1830691@tongji.edu.cn
} 
(4) Aluminate cement : Zhengzhou Jiannai Special Aluminate Co., Ltd. CA50-A600 aluminate cement, active alumina content of $59 \%$.
(5) Sand : standard sand.

\subsection{Specimen preparation}

Table 1. Chemical composition of cement.

\begin{tabular}{ccccccccc}
\hline Items & $\mathrm{CaO}$ & $\mathrm{SiO}_{2}$ & $\mathrm{Al}_{2} \mathrm{O}_{3}$ & $\mathrm{Fe}_{2} \mathrm{O}_{3}$ & $\mathrm{MgO}$ & $\mathrm{SO}_{3}$ & $\mathrm{TiO}_{2}$ & $\mathrm{~K}_{2} \mathrm{O}$ \\
\hline Content $/ \%$ & 63.30 & 21.88 & 4.51 & 2.35 & 1.63 & 2.91 & 0.20 & 0.55 \\
\hline
\end{tabular}

Table 2. Chemical composition of FGD gypsum.

\begin{tabular}{cccccccc}
\hline Items & $\mathrm{CaO}$ & $\mathrm{SiO}_{2}$ & $\mathrm{Al}_{2} \mathrm{O}_{3}$ & $\mathrm{SO}_{3}$ & $\mathrm{Fe}_{2} \mathrm{O}_{3}$ & $\mathrm{MgO}$ & Loss \\
\hline Content $/ \%$ & 31.6 & 2.7 & 0.7 & 42.4 & 0.5 & 1.0 & 19.2 \\
\hline
\end{tabular}

Table 3. Mix proportion of complex cementitious system.

\begin{tabular}{ccccccccc}
\hline Sample & $\begin{array}{c}\text { P.II 42.5 } \\
/ \mathrm{g}\end{array}$ & $\begin{array}{c}\mathrm{FGD} \\
\text { gypsun/g }\end{array}$ & $\begin{array}{c}\text { Slag } \\
\text { powder/g }\end{array}$ & $\begin{array}{c}\text { Aluminate } \\
\text { cement/g }\end{array}$ & $\begin{array}{c}\mathrm{SO}_{3}: \mathrm{Al}_{2} \mathrm{O}_{3} \\
/ \mathrm{g}\end{array}$ & $\begin{array}{c}\text { Water } \\
/ \mathrm{g}\end{array}$ & $\begin{array}{c}\mathrm{Sand} \\
/ \mathrm{g}\end{array}$ & $\begin{array}{c}\mathrm{SO}_{3} \\
/ \%\end{array}$ \\
\hline $\mathrm{S} 0$ & 225 & 0 & 225 & 0 & $/$ & 225 & 1350 & $/$ \\
$\mathrm{S} 1$ & 225 & 40 & 135 & 50 & 0.5 & 225 & 1350 & 4.7 \\
$\mathrm{~S} 2$ & 225 & 60 & 135 & 30 & 1.0 & 225 & 1350 & 7.8 \\
$\mathrm{~S} 3$ & 225 & 72 & 135 & 18 & 1.5 & 225 & 1350 & 9.4 \\
\hline
\end{tabular}

Note: desulfurization gypsum in the table is desulfurization gypsum calcined at $800{ }^{\circ} \mathrm{C} ; \mathrm{SO}_{3}$ is calculated according to sulfate content in desulfurization gypsum and $\mathrm{Al}_{2} \mathrm{O}_{3}$ is calculated according to alumina content in aluminate cement.

The water-binder ratio of this test specimen is 0.5 , and the samples of each group as shown in Table 3 were prepared according to different ratios. The steam curing system adopted in this experiment is as follows: $20{ }^{\circ} \mathrm{C}$, curing for $2 \mathrm{~h}$, heating up to $60{ }^{\circ} \mathrm{C}$ within $2 \mathrm{~h}$, then constant temperature for $6 \mathrm{~h}$, and the temperature decreased from $60{ }^{\circ} \mathrm{C}$ to $20{ }^{\circ} \mathrm{C}$ in the last $2 \mathrm{~h}$.

\subsection{Test content and method}

\subsubsection{Thermal activation of desulfurization gypsum}

The results show that the activity of desulfurization gypsum is improved after calcination at $800{ }^{\circ} \mathrm{C}$, which is beneficial to improve the mechanical properties of desulfurization gypsum, so desulfurization gypsum is calcined at $800{ }^{\circ} \mathrm{C}$ in advance ([2]). The desulfurization gypsum was calcined in the DRY-36 high temperature industrial furnace of Shanghai Kecheng Company. The calcination system was as follows: heating up from room temperature to $800{ }^{\circ} \mathrm{C}$, and constant temperature for $1 \mathrm{~h}$, and then reduced to room temperature. In addition, the desulfurization gypsum before thermal activation and the desulfurization gypsum after activation were tested by XRD and the particle size was analyzed.

\subsubsection{Determination of workability of composite cementitious system}

The samples were prepared according to the proportion of Table 4, and the setting times and fluidity of each group were determined according to the national standard GB 175-2007 "Comon Portland cement" and GB/T 2419-2005 "Test method for fluidity of cement mortar".

\subsubsection{Determination of mechanical properties of composite cementitious system}

The specimens were prepared according to the proportion of Table 4, and the compressive strengths and tensile strengths of each group were determined with reference to the national standard GB/T 17671-1999 "Method of testing cements-Determination of strength" and CECS 13-2009 "Standard test methods for fiber reinforced concrete".

\subsubsection{Determination of volume stability of composite cementitious system}

The free expansion rates and limited expansion rates were determined according to the standard JC/T6032004 "Standard test method for drying shrinkage of mortar" and the standard JC 476-2001 "Expansive agents for concrete". 


\subsubsection{Determination of hydration products in composite cementitious system}

The basic parameters of the instrument were determined by X-ray diffractometer: the target is standard monochromatic $\mathrm{CuK} \alpha$, the voltage is $40 \mathrm{kV}$, and the current is $20 \mathrm{~mA}$. The hydration samples were tested with a scanning step of $0.05^{\circ} / 2 \theta, 2$ s per step and a scanning range of $5^{\circ} \sim 70^{\circ}$. The prepared hydration samples were tested in an X-ray diffractometer with adjusted parameters.

\subsubsection{Determination of ettringite content}

Table 4. Particle size distribution of FGD gypsum.

\begin{tabular}{llcccc}
\hline Sample types & $>80 \mu \mathrm{m} / \%$ & $60-80 \mu \mathrm{m} / \%$ & $40-60 \mu \mathrm{m} / \%$ & $20-40 \mu \mathrm{m} / \%$ & $<20 \mu \mathrm{m} / \%$ \\
\hline Calcined FGD gypsum & 0.13 & 1.32 & 7.93 & 20.32 & 70.30 \\
Original FGD gypsum & 0.36 & 2.57 & 16.64 & 32.92 & 47.51 \\
\hline
\end{tabular}

The related studies show ([5]) that ethylene glycolmethanol solvent can extract AFt, from cement hydration products with $98 \%$ high selectivity, thus determining the content of $\mathrm{Al}_{2} \mathrm{O}_{3}$ in the extract to characterize the content of AFt in the composite cementitious material system.

\section{Test results and analysis}

\subsection{Performance analysis of desulfurization gypsum}

In this experiment, the particle size analysis and XRD test of desulfurization gypsum after thermal activation and desulfurization gypsum before activation are carried out. The test results are shown in Table 4 and Fig. 1 respectively.

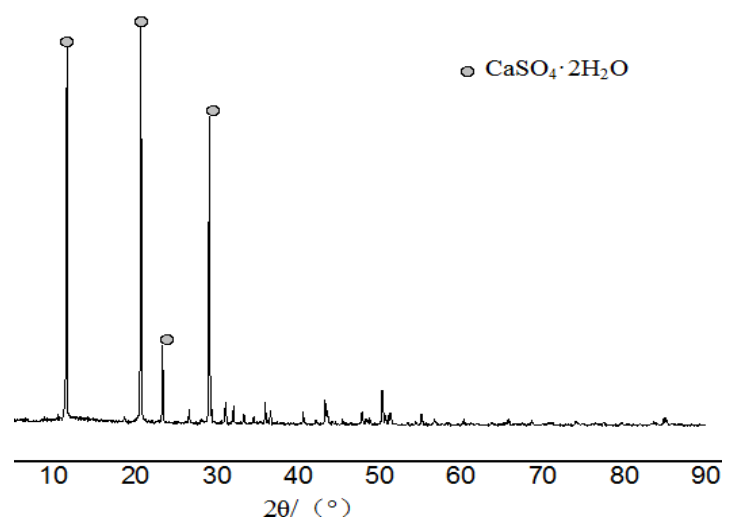

(a) Original FGD gypsum

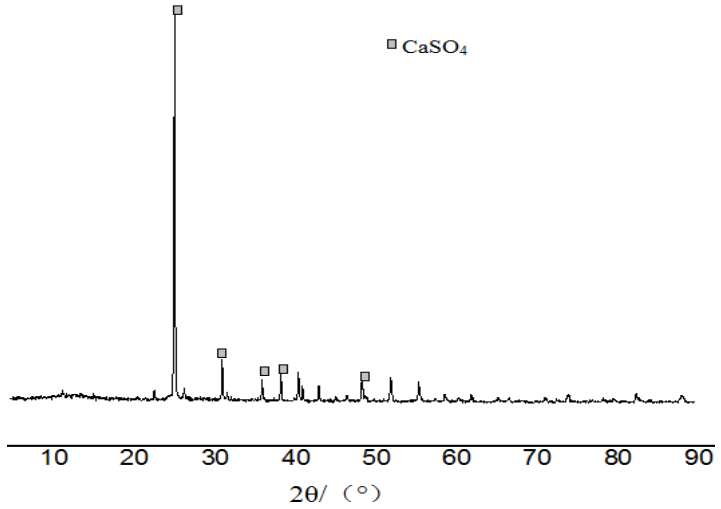

(b) Calcined FGD gypsum

Fig. 1. XRD images of FGD gypsum

It can be found from Table 4 that the particle size of desulfurization gypsum after thermal activation at $800{ }^{\circ} \mathrm{C}$ is significantly smaller than that of inactivated desulfurization gypsum, which may be due to the dehydration of inactivated desulfurization gypsum. Through Fig. 1, it is known that the unactivated desulfurization gypsum is dihydrate gypsum with strong and sharp peak value, complete crystal form and good crystallinity, and after thermal activation at $800{ }^{\circ} \mathrm{C}$, the dehydrate gypsum is transformed into anhydrous gypsum. It is also confirmed that the particle size distribution changed from large to small, and it also showed that the volume expansion of anhydrous gypsum will occur when it is changed from anhydrous gypsum to dihydrate gypsum ([5]).

\subsection{Workability of slurry in composite cementitious system}

According to the national standard ("General Portland cement" GB175-2007), the setting time and fluidity of composite cementitious system pastes were measured, and the following results were obtained (Fig. 2). 


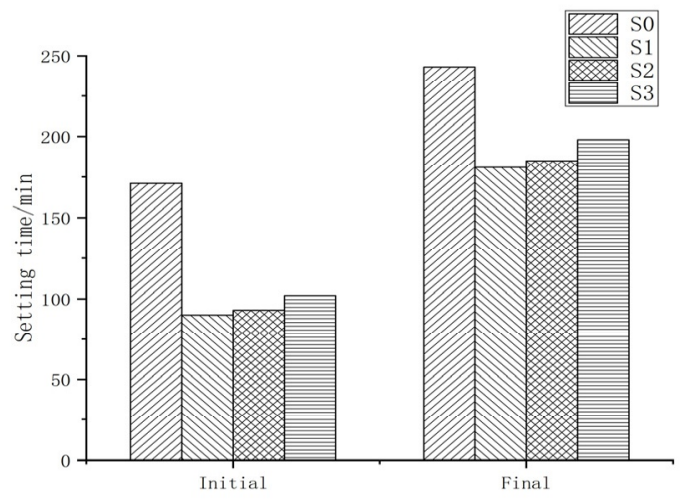

(a) Setting time

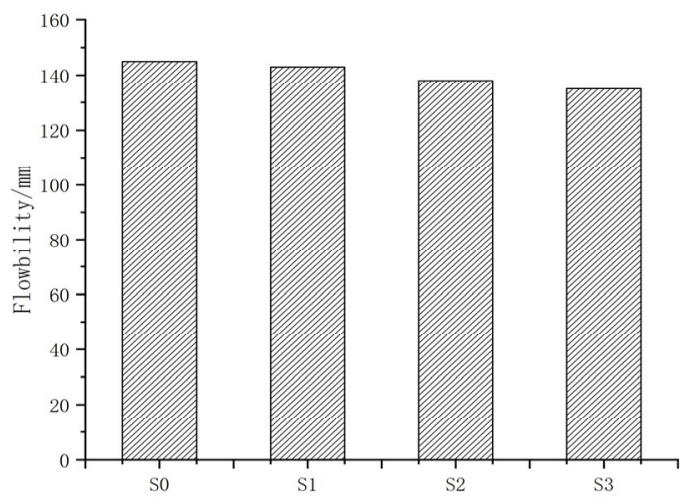

(b) Flowbility

Fig. 2. Workability of composite cementitious mortar

From Fig. 2 (a), it can be seen that after adding desulfurization gypsum and aluminate cement instead of part of slag powder, the initial setting times and final setting times of pastes are obviously shortened, that is, the initial and final setting times of S1, S2 and S3 is less than those of S0. However, all of them accord with the setting time standard of " Comon Portland cement ". This is due to the rapid reaction of the mixed aluminate cement with the desulfurization gypsum in the composite system to form ettringite, which shortens the setting times of the composite cementitious system ([2],[5],[12]), and with the increase of the ratio of sulfur to aluminum, the setting times of the composite cementitious system are prolonged.

From Fig. 2 (b), it can be found that the slurry fluidity of the composite cementitious system decreases with the increase of the ratio of sulfur to aluminum. From 3.1, the desulfurization gypsum added in this experiment is anhydrous gypsum calcined at $800{ }^{\circ} \mathrm{C}$. The water absorption of anhydrous gypsum should be transformed into dihydrate gypsum, so with the increase of the content of anhydrous desulfurization gypsum, that is, the increase of S/Al ratio, The water requirements of the whole cementitious system increase, and the fluidity of the slurry decreases under the condition of keeping the water consumption unchanged ([4]).

\subsection{Compressive strength of paste in composite cementitious system}

The compressive strengths of pastes were measured at $1 \mathrm{~d}$, 7d, 28d, 40d, 60d, 90d and 180d under steam curing system. The test results are shown in Fig. 3.

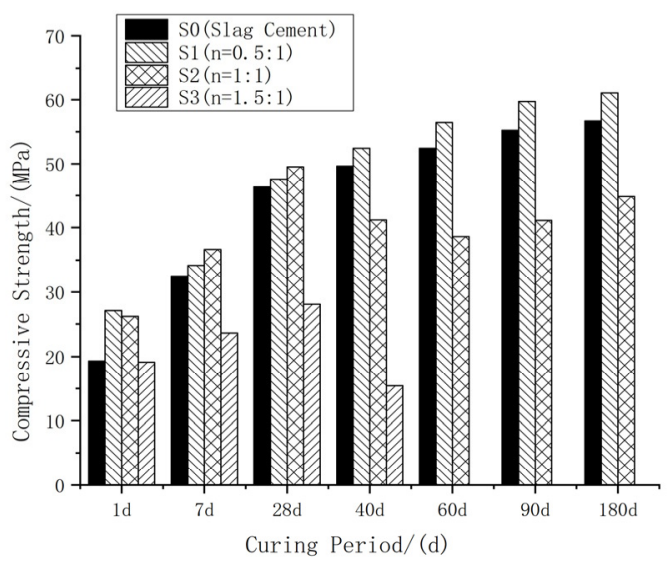

Fig. 3. Compressive strength of composite cementitious system mortar

From Fig. 3, it can be seen that the compressive strength of S1 are significantly higher than those of S0, and the compressive strengths of S1 are 34\% higher than those of S0, and the compressive strengths of S1 are higher than those of S0. This shows that the addition of desulfurization gypsum and aluminate cement can improve the compressive strength of the composite cementitious system, especially the early compressive strength, because the addition of desulfurization gypsum and aluminate cement can promote the formation of early ettringite so that its internal structure becomes compact. In addition, with the progress of hydration reaction, the compressive strengths of S0 and S1 still increased after 60 days, which was due to the secondary hydration of slag powder ([14-15]), and the hydration products filled the internal void of mortar and improved the strength.

Before 28 days, the compressive strengths of S2 were higher than those of S0, which was also due to the addition of desulfurization gypsum and aluminate cement. And it promoted the formation of ettringite and compacted the internal structure of the pastes. After 28 days, the compressive strengths of S2 decreased obviously. It was due to the increase of the ratio of sulfur to aluminum, which led to the formation of more ettringite, coupled with the larger expansion in the structure of dihydrate gypsum formed by water absorption and crystallization of some excess anhydrous gypsum. A certain number of microcracks were formed, which adversely affected the strength ([2]). In addition, the strengths of S3 shrinked after 28 days, which may be due to the high ratio of sulfur to aluminum and the formation of too much ettringite in the early stage. It resulted in volume expansion and the formation of more microcracks in the specimens. It was not until 40 days that the specimens began to crack. ([5]). 
To sum up, under the condition of low ratio of sulfur to aluminum $(\mathrm{n}=0.5: 1)$, a small amount of calcined desulfurization gypsum and aluminate cement instead of slag powder can promote the formation of ettringite and improve the compressive strength of the composite cementitious system. When the ratio of sulfur to aluminum $(n=1.5: 1)$ was too high, the formation rate of ettringite was too fast and the amount of ettringite was too much. In addition, some of the excess anhydrous gypsum absorbed water and crystallizes to form dihydrate gypsum, which leaded to the expansion of the samples, even cracking and damage.

\subsection{Volume stability of slurry in composite cementitious system}

In order to further explore the effect of different ratio of sulfur to aluminum on the volume stability of composite cementitious system, the free expansion rate, limited expansion rate test and tensile strength test of each group of samples were carried out according to the corresponding standards.

\subsubsection{Free expansion rate}

Fig. 4 shows the test results of free expansion rate of composite cementitious system slurry.

As shown in Fig. 4, compared with the blank samples, the composite cementitious system with desulfurization gypsum and aluminate cement changed from the shrinkage stage to the expansion stage earlier, it may be because of the addition of desulfurization gypsum and aluminate cement. The formation of ettringite in the pastes was promoted, the shrinkage of cement was compensated, and the volume of the pastes changed from shrinkage to expansion. With the increase of the ratio of sulfur to aluminum, the slurry changed from shrinkage to expansion earlier. For example, S1 entered the expansion stage after 7 days, S2 entered the expansion stage after 4-5 days, and $\mathrm{S} 3$ entered before 3 days. This is because with the increase of the ratio of sulfur to aluminum, the amount of ettringite formed in the early stage of the system is more, and the expansion effect is significant, thus significantly shortened the shrinkage stage.

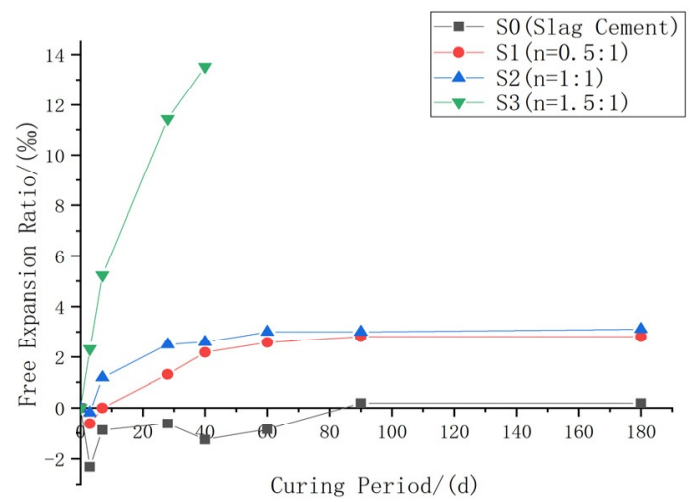

Fig. 4. Free expansion rate of mortar in composite cementitious system
After entering the expansion stage, the free expansion rate of S1 and S2 showed a steady trend after rapid growth, while the expansion rate of $\mathrm{S} 3$ was too large after 28 days, resulting in cracking, which also confirmed the test results of compressive strength. This is also because: with the increase of the ratio of sulfur to aluminum, the amount of ettringite increases, resulting in varying degrees of expansion, and the compressive strength had different effects: under the condition of low sulfur-aluminum ratio $(\mathrm{n}=0.5: 1)$, the amount of ettringite was appropriate. The moderate expansion is beneficial to the increase of compressive strength. Under the condition of high ratio of sulfur to aluminum $(n=1$ : $1, \mathrm{n}=1.5: 1)$, the amount of ettringite was too much, and some excess anhydrous gypsum absorbed water and crystallizes to form dihydrate gypsum, and the expansion caused a certain degree of damage to the structure of the slurry. It even leaded to cracking directly.

\subsubsection{Limited expansion rate and tensile strength test}

In order to further explore the volume stability of the composite cementitious system, and intuitively explain the influence of the expansion stress caused by expansion on the macroscopic properties of the pastes, according to the test results of free expansion rate and compressive strength, In this paper, the limited expansion rates and tensile strengths of S1-S3 groups were tested for 7 days, 28 days, 40 days, 60 days, 90 days and 180 days, and the expansion stresses were calculated by formula (1) ([2]). The results of each group are compared with the results of tensile strength test, and the results are shown in Fig. 5.

$$
\sigma=\mu^{*} \mathrm{E}^{*} \varepsilon
$$

note : $\sigma$ - Expansion stress; $\mu$ - Reinforcement ratio, the reinforcement ratio of this test is $0.78 \%$;E- Limiting elastic modulus of steel bar, $\mathrm{E}=2 \times 10^{5} \mathrm{Mpa} ; \varepsilon$ - Limited expansion rate for all ages measured.

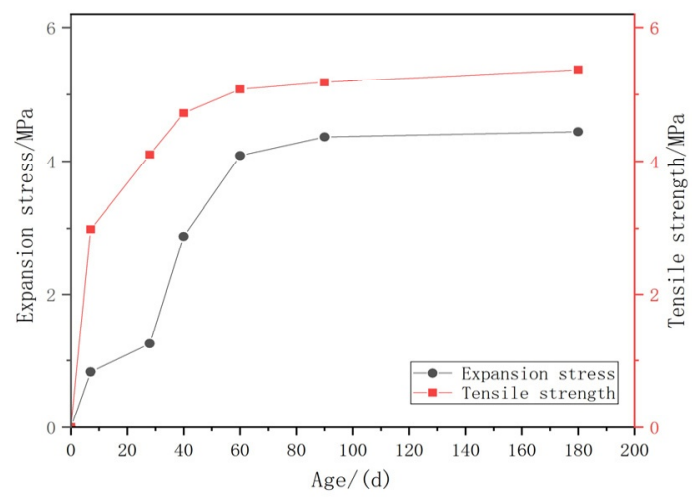

(a) $\mathrm{S} 1$ 


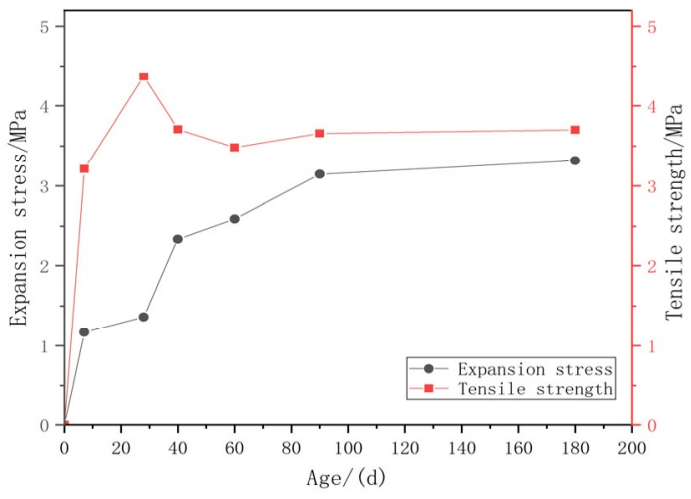

(b) S2

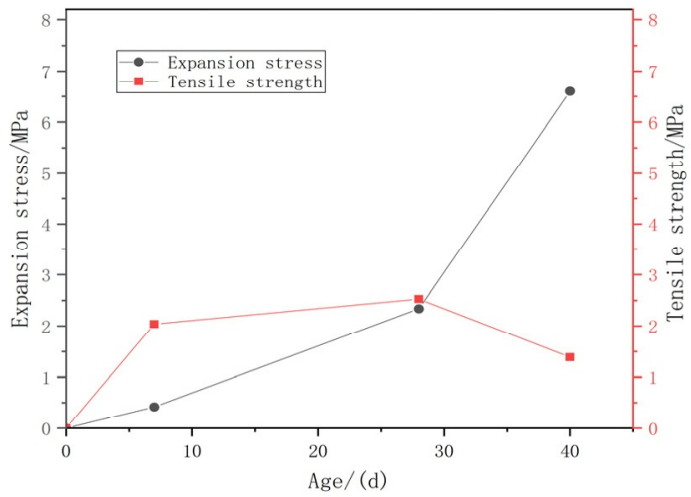

(c) S3

Fig. 5. Expansion stress and tensile strength of S1, S2 and S3

From Fig. 5 (a) and (b), it can be seen that the expansion stresses of 0d-180d in S1 and S2 were less than the corresponding tensile strengths, and tended to be stable after 90 days, and its changing trend and compressive strength confirmed each other. After 28 days, the expansion stresses of S2 increased rapidly, but the tensile strengths decreased rapidly, which indicated that the hydration product expansion in the slurry leaded to some damage to the structure. But after 60 days, the tensile strengths increased gradually and the expansion stresses tended to be stable. This may be because the product of the hydration reaction filled the cracks and voids. From Fig. 5 (c), it can be seen that the expansion stresses of S3 were less than the tensile strengths before 28 days, and the expansion stresses were obviously higher than the tensile strengths at 40 days, so the specimens had obvious cracking phenomenon at 40 days, which leaded to the decrease of tensile strength. At the same time, it proved that the compressive strengths of S3 in 2.3 decreased until the damage was caused by expansion in 40 days.

\subsection{Determination of hydration products of slurry in composite cementitious system}

In order to find out the root cause of the expansion of the composite cementitious system and verify the previous conjecture of the macroscopic properties, the XRD test and analysis of the samples in different ages were carried out, and the results are shown in Fig. 6:

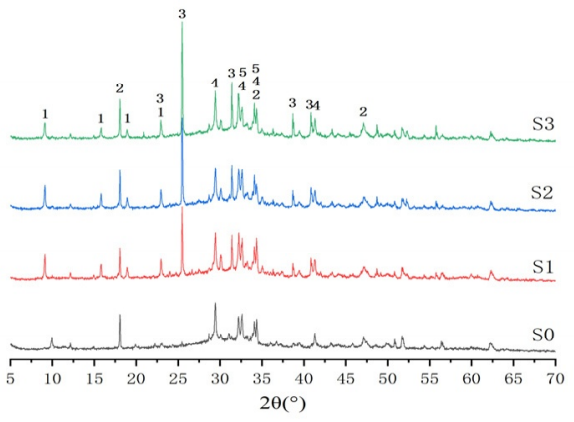

(a) $1 \mathrm{~d}$

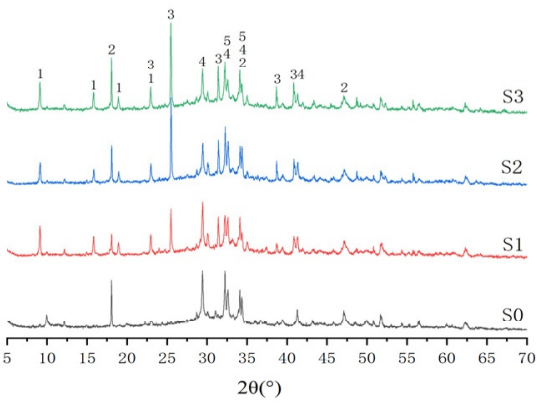

(b) $3 \mathrm{~d}$

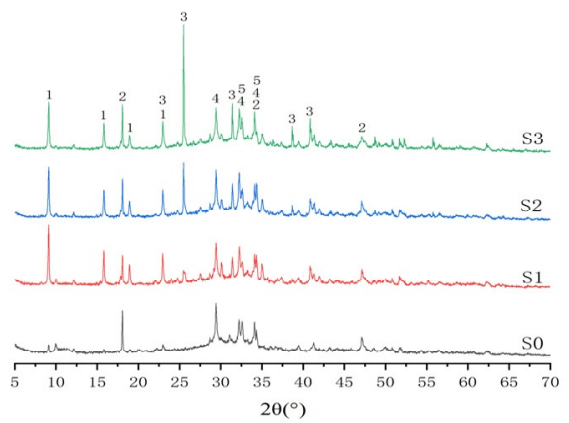

(c) $7 \mathrm{~d}$

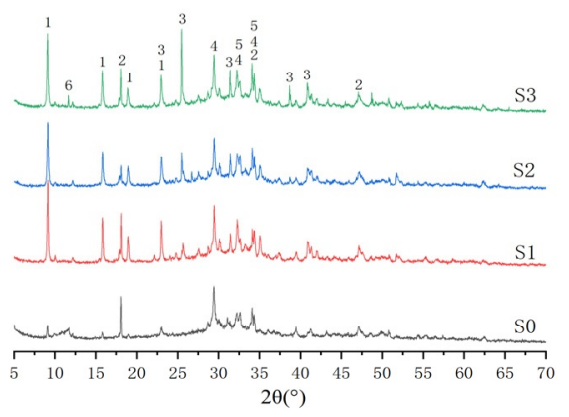

(d) $28 \mathrm{~d}$ 


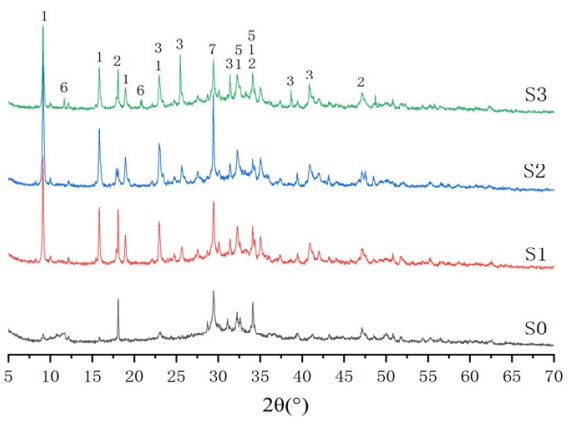

(e) $40 \mathrm{~d}$

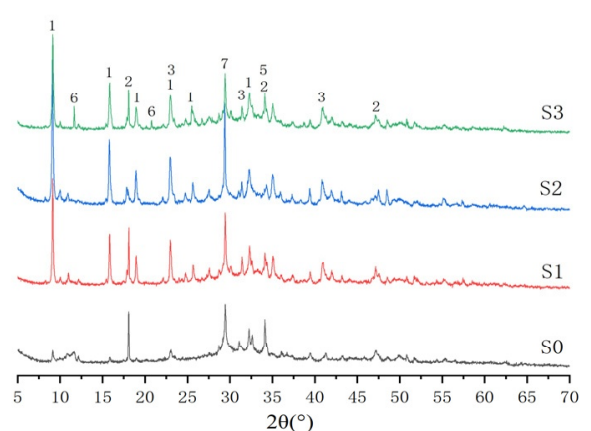

(f) $60 \mathrm{~d}$

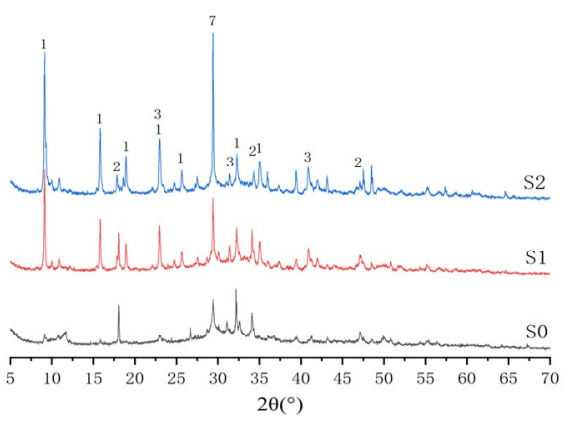

(g) $90 \mathrm{~d}$

Fig. 6. XRD of each group at different ages

Note: 1-AFt, 2-Ca(OH) $2, \quad 3-\mathrm{CaSO}_{4}, \quad 4-\mathrm{C}_{3} \mathrm{~S}, \quad 5-\mathrm{C}_{2} \mathrm{~S}, \quad 6-$ $\mathrm{CaSO}_{4} \cdot 2 \mathrm{H}_{2} \mathrm{O}, \quad 7-\mathrm{CaCO}_{3}$

From Fig. 6, it can be found that the components of each group are roughly the same, mainly ettringite, calcium hydroxide, unhydrated $\mathrm{C}_{3} \mathrm{~S}$ and $\mathrm{C}_{2} \mathrm{~S}$ (early stage), calcium sulfate, calcium carbonate, etc., while S0 was less than $\mathrm{S} 1, \mathrm{~S} 2, \mathrm{~S} 3$, the peak of $\mathrm{CaSO}_{4}$ is missing. This is because S1, S2 and S3 all add thermally activated desulfurization gypsum, which is consistent with the ratio of raw materials. Ettringite was formed in S1, S2 and S3 from $1 \mathrm{~d}$, and the corresponding peak height of ettringite increased with age, and the peak height of ettringite increased gradually with the increase of S / Al ratio, while ettringite formed in S0 from $7 \mathrm{~d}$. And the peak of ettringite is low in the whole curing cycle. This phenomenon confirms that the expansion of the previous article is mainly caused by the formation of ettringite. In addition, $\mathrm{CaSO}_{4} \cdot 2 \mathrm{H}_{2} \mathrm{O}$ was formed after 28 days, which was due to the large amount of desulfurization gypsum, and some excess anhydrous gypsum crystallized to form dihydrate gypsum after 28 days, and the volume expanded. Therefore, it can be proves that S3 bears not only the expansion caused by the formation of ettringite, but also the volume expansion caused by the formation of dihydrate gypsum from 28 days, which proves that the expansion stresses of S3 increase sharply and the compressive strengths decrease sharply after 28 days. The final specimen cracked and destroyed after 40 days, and the strengths of $\mathrm{S} 2$ decreased at 40 days for the same reason.

\subsection{Determination of ettringite content in composite cementitious system}

It is known from the previous paper that the formation of ettringite is the main factor leading to expansion. Therefore, in order to explore the mechanism of ettringite expansion caused by ettringite, the determination of ettringite content in each age of composite cementitious system was also carried out. The results are shown in Fig. 7.

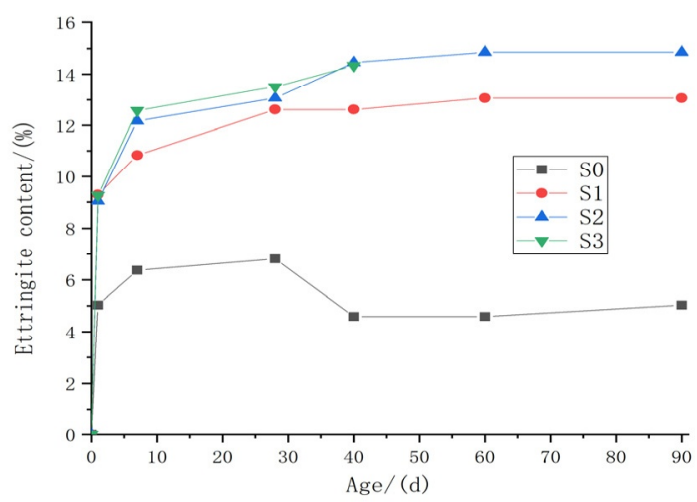

Fig. 7. Ettringite content at different ages

From Fig. 7, it can be found that the ettringite content increases with the increase of the ratio of sulfur to aluminum, and the ettringite contents of S1, S2, S3 are obviously higher than that of S0, which indicates that the increase of desulfurization gypsum promotes hydration, thus the ettringite content increases. The ettringite contents of the four groups of composite cementitious systems increased rapidly in the early stage (before 7 days), but in the $7 \mathrm{~d}-28 \mathrm{~d}$ stage, the increase of S0 was small, and S1, S2, S3 increased obviously, which was due to the addition of desulfurization gypsum. It promotes the formation of ettringite. After 28 days, the content of S0 ettringite decreased at first and then increased slowly, which was due to the crystal transformation of a small amount of ettringite (from AFt to AFm), followed by the secondary hydration of slag powder). The ettringite content increased gradually. On the other hand, the content of S1 ettringite increased slowly and tended to be stable, which is similar to the corresponding compressive strength. At $40 \mathrm{~d}$, the content of ettringite increased obviously, and its volume expansion reflected the compressive strength, that is, the 
compressive strengths of S2 and S3 decreased obviously at $40 \mathrm{~d}$. But after $40 \mathrm{~d}$, due to the high content of ettringite and the formation of dihydrate gypsum, S3 began to crack, and the content of S2 ettringite increased slowly and tended to be stable, so the compressive strengths increased slowly in the later stage.

\section{Conclusion}

In this study, the composite cementitious system of desulfurization gypsum, aluminate cement and slag powder cement was formed by adding appropriate amount of calcined desulfurization gypsum and aluminate cement into Portland cement-slag powder cementitious system. Its working properties, mechanical properties, volume stability and hydration products were studied. The results show that:

(1) The addition of calcined desulfurization gypsum and aluminate cement will shorten the initial and final setting times of the composite cementitious system, and with the increase of the ratio of sulfur to aluminum in the cementitious system, the early ettringite content increases and is coated on the surface of unhydrated particles. As a result, the initial and final setting times are prolonged and the fluidity is reduced.

(2) When the ratio of sulfur to aluminum is $0.5: 1$, the compressive strengths of calcined desulfurization gypsum-aluminate cement-slag powder cement composite system increase by $34 \%$ in 1 day and $8 \%$ in 180 days, which is due to the addition of calcined desulfurization gypsum and aluminate cement. The production of ettringite increases significantly, so as to improve the early and late compressive strengths of silicate-slag powder system, especially the early strength.

(3) With the increase of the ratio of sulfur to aluminum in the cementitious system, the amount of ettringite increases gradually, so the free expansion rate shows an increasing trend. When the ratio of sulfur to aluminum is less than $1: 1$, the free expansion rate is less than $0.6 \%$. When the ratio of sulfur to aluminum is higher than 1: 1, the expansion stress is close to or greater than the tensile strength of the specimen, due to the continuous formation of ettringite and the formation of dihydrate gypsum, which leads to the decrease of strength and even cracking. The volume stability is poor.

(4) The hydration products of the composite cementitious system are mainly $\mathrm{AFt}, \mathrm{Ca}(\mathrm{OH})_{2}$ and C-S$\mathrm{H}$, and a small amount of ettringite is transformed into AFm. In addition, the characteristic peak of gypsum dihydrate appears in the hydration process. The results show that some of the excess anhydrous gypsum absorbs water and crystallizes to form dihydrate gypsum.

\section{References}

1. Telesca A, Marroccoli M, Calabrese D, et al. Flue gas desulfurization gypsum and coal fly ash as basic components of prefabricated building materials[J]. Waste Management, 2013, 33 (3): 628-633.

2. Zhang Y, Pan F, Wu R. Study on the performance of FGD gypsum-metakaolin-cement composite cementitious system[J]. Construction and Building Materials, 2016, 128: 1-11.

3. Lei D-Y, Guo L-P, Sun W, et al. Study on properties of untreated FGD gypsum-based high-strength building materials $[\mathrm{J}]$. Construction and Building Materials, 2017, 153: 765-773.

4. Rodvinij P. The Effect of Fgd Gypsum Addition in the Mixture of Shotcrete Used Bottom Ash as Fine Aggregate[J]. International Journal of GEOMATE, 2019, 16 (57)

5. Zhang Y J, Yu P, Pan F, et al. The synergistic effect of AFt enhancement and expansion in Portland cement-aluminate cement-FGD gypsum composite cementitious system[J]. Construction and Building Materials, 2018, 190: 985-994.

6. Jiang L, Li C, Wang C, et al. Utilization of flue gas desulfurization gypsum as an activation agent for high-volume slag concrete[J]. Journal of Cleaner Production, 2018, 205: 589-598.

7. $\mathrm{Xu} \mathrm{L}, \mathrm{Wu} \mathrm{K}, \mathrm{Li} \mathrm{N}$, et al. Utilization of flue gas desulfurization gypsum for producing calcium sulfoaluminate cement[J]. Journal of Cleaner Production, 2017, 161: 803-811.

8. ZHAO Qian, FANG Zhou. Study of Hydraulic Cementing Materials Based on Steel Slag-activated Desulfurization Gypsum [J]. Materials Reports, 2015,29(08):130-133. (in Chinese)

9. SHI Huisheng, LIU Hongyan. Resource Recovery of Flue Gas Desulfurization Gypsumin Slag Cement [J]. Journal of Tongji University(Natural Science), 2008(01):66-70. (in Chinese)

10. SHI Huisheng, GUO Xiaolu, LIU Hongyan. Influence of Flue Gas Desulfurization Gypsum on Resistance of Permeability of Slag Concrete [J]. Journal of Tongji University(Natural Science), 2009,37(05):656-659. (in Chinese)

11. QIAN Daxing, SUN Li. Effects of Desulfurization Gypsum on the Composite Cementitious Material of Concrete Mechanical Properties [J]. Non-Metallic Mines, 2013,36(04):63-65. (in Chinese)

12. SHEN Yan, CHEN Xi, ZHANG Wei, LI Xuepiao. Current Status of Industrial Waste Residue in the Production of Sulphoaluminate Cement [J]. Materials Reports ,2018, 32(S2):489-491+497. (in Chinese)

13. ZHANG Yongjuan, WU Rong, ZHANG Xiong. Flue Gas Desulfurization Gypsummetakaolincement Compound Cementitious System [J]. Journal of Tongji University(Natural Science), 2015,43(05):754-758. (in Chinese)

14. Bellmann F, Stark J, Matschei T. Hydration behaviour of sulphate-activated slag cements[J]. Chinese Nursing Research, 2005. 
15. Huang Y, Lin Z. Investigation on phosphogypsumsteel slag-granulated blast-furnace slag-limestone cement $[\mathrm{J}]$. Construction and Building Materials, 2010, 24 (7): 1296-1301.

16. LIAO Gaoyu, ZHU Mintao, ZHANG Yongjuan, WANG Shiwei. Research on Cement-FGD gypsumslag Composite Cementitious System under Steam Curing Conditions $[\mathrm{J}]$. Fly Ash Comprehensive Utilization, 2015(01):16-22. (in Chinese) 